\title{
CASES OF CHOREA.
}

\author{
BY W. B. HADDEN, M.D.
}

\section{A. Complete lose of Articulation in Chorea.}

Cask I.-A. L. æt. 7, female, was admitted into St. Thomas's Hospital, under Dr. Bristowe, on January 10th, 1879. . She had never had acute rheumatism. Eight months before admission she had been under treatment on the surgical side for chronic abscesses around the kneojoint. Her present illness began two weeks ago, with movements chiefly affecting the right side. On admission, the chorea was found to be general, but most marked in the face, tongue, and right side. There was great difficulty in articulation, and also some dysphagia. She had tinea tarsi on the right side, and several chronic indolent ulcers on right leg and thigh, apparently the result of bone disease. No cardiac murmur was detected. On January 19th it was found that she could not speak. Next day she made an attempt, said "yes" and "no," but refused her name. On January 22nd she had recovered speech, but the words were jerked out, and syllables often mispronounced and slurred. The day following she was very quiet, and speech was again entirely lost. The muscles of the face were less affected, and the tongue protruded more easily. The temperature the previous evening was $102^{\circ} \cdot 2$. On January 24th, that is two days later, she could say a good many words quite distinotly, protruded her tongue quietly, and was altogether better. On February 3rd she was again unable to articulate, and the movements of the legs were markedly choreic. On February 18th, she could say several words distinctly, and repeat her name. From that time she steadily improved, and was discharged cured on March 19th.

Case II.-S. G., æt. 14, female, was admitted under Dr. Stone, on May 27th, 1879. She had never bad acute rheumatism, but there was a history of fright just before present attack. On admission, she had general, but not very violent, choreic movements. The speech was slow, but not otherwise affected. She could not feed herself, and swillowed with difficulty. On 
June 26th she was found to have lost all power of articulation, and this continued for more than a week. I found that the right hand was decidedly weak, and that there was anæsthesia of left arm and slightly of left leg. There was a soft systolic murmur at the apex of heart. She was discharged relieved on August 6th.

Ca8k III. S. R., mt. 12, female, was admitted under Dr. Harley, on May 30th, 1883. She had had acute rheumatiom when six years old. In January, 1883, she had another attack which was very severe, and was followed by chorea and loss of speech. On admission, the movements were general, but most marked on right side. She could not articulate, but the next day she said a few words. On June 14th it was noted that the patient not only does not talk, but makes no attempt to frame words, and did not even try to speak to her mother. She protruded the tongue when asked. Since the previous day she had screamed much, and was very restless. On June 16 th she could talk a little, and from that time continued to improve. There was a systolic murmur at the apex. She was discharged cured, on July 19th.

Remarks.- It is a curious and suggestive fact that, in all the cases the choreic movements were most marked on the right side, and in one that there was decided paresis of the right arm. The inability to articulate seems comparable to the paralysis of limbs, which may either precede or follow an attack of chorea. But whether the actual cause lay in the brain itself, or in the medulle, or in the exhausted muscle, I am not prepared to say.

\section{B. Ansesthesia in Chorea.}

Case I.-E. M., øt. 20, female, was admitted under Dr. Harley on May 6th, 1879. She had had convulsions during dentition, and acute rheumatism ten years ago. Six reeks ago she had a severe fall, and was much frightened. Three days later, movements began in the left arm, and were limited to that part until ten days before admission, when the chorea became general. About this time she was said to have had another fright, and since then her memory has become impaired, and she has had delusions. On admission, there were general choreic movements, but the left side was much more affected than the right. The left arm and leg, too, were very weak. The speech was but little impaired, and there was no difficulty in deglutition. These was total anæsthesia of left arm and leg, and partial anæesthesia of right arm. Her mental condition was much impaired. She did not know how long 
she had been in the hospital, but she answered readily when spoken to, and had no delusions. There was no cardiac affection. On May 9th she became very restless and violent. She now had distinct delusions. She thought she was going to be poisoned, and that she would never see her parents again. At this time she was being treated with conium. On May 2sth she developed well-marked symptoms of coniumpoisoning, and accordingly the drug was omitted. The same treatment was subsequently resumed, but without benefit. On June 22nd she tried to drink a bottle of carbolic acid, but was fortunately observed. On July 9th, however, she was found with an empty bottle, labelled "poison," which had previously contained 3 vij of a solution consisting of morph. acet. gr. $t$, and atropiæ sulph. gr. $\frac{1}{60}$ in ten minims. It was not until two hours and a half later that any symptoms were observed. It was then noticed that she tottered when walking. She soon went to sleep, and four hours after the solution was taken, she was apparently sleeping quietly. Half an hour later she was heard to graan feebly, the lips were blue, and the respiration seemed to have ceased. The extremities were very cold, the pupils dilated, the conjunctivæ insensible. Artificial respiration was kept up for twenty-six hours, and stimulants administered. No spontaneous effort at breathing was observed for twenty-four hours. She was comatose thronghout, but could easily be aroused by shaking. Her mental condition was more unsatisfactory than before. She subsequently acknowledged to taking the poison, bat said she poured some away. She was discharged on July $22 n d$, and I believe went to an asylum.

CAse II.-E. R., æt. 15, female, was admitted under Dr. Ord on Jan. 22nd, 1879. Her mother and eldest sister were liable to faints, but there was no decided neurotic or other taint in the family. The patient had never had acute rheumatism or scarlet fever, but for the last six months she had been under treatment for enlarged glands in the neck. A month ago she began to have twitching of the left hand, then the face became affected, and lastly the leg. On admission, there were slight choreic movements of the head, left arm and both legs. There was also paresis of the left arm. It was found that there was anrsthesia of the left arm and leg. A systolic murmur was audible over the pulmonary artery. She was discharged cured on March 19th.

CAsE III.-E. B., æet. 16, female, was admitted under Dr. Bristowe on June 25th, 1879. She had had rheumatic fever, and five-and-a-half years ago was attacked with chorea. She had a second attack three months later, and from that time until May 1st, 1879, there were occasional tremblings of the 
hands, feet, and face. On that day she had a fresh attack of rheumatism, which was followed by chorea. The movements affected both hands and feet, and slightly the face. The power of the right hand was much impaired, although the movements were less evident here than on the opposite side. She did not feel when a needle was thrust into the right leg, but flinched when touched with a pin on the left leg. Her mental condition was fairly good, but occasionally she valled out in her sleep. There was a mitral systolic murmur. On July 8th, sensation began to return in right leg, and on the 18th, there was only a little difference between the two sides. She was discharged cured on July 27th.

Romarks. - I am inclined to think that there is no rule as regards the distribution of the anesthesia in chorea. In Cases I. and II., as well as in two or three others which I have observed, the impairment of sensation was on the side most affected by the movements. In Case III., however, it will be seen that the ancosthesia was chiefly in the right side, wherees the choreic movements were mainly left-sided.

\section{. . Hysteroid Convulaive Attacks in Chorea.}

C. W., æt. 15, male, was admitted under Dr. Bristowe on January 16th, 1882 . On December 20th he suddenly became faint and sick, and fell on his face. He was helped up, but a few minutes later he fell again, and began to kick about. $\mathrm{He}$ had some half-dozen such attacks on the same day. The choreic movements are said to date from this time. The boy was found in the casualty room, lying on a couch, with the body rigid, and working his arms and legs about. He was quite conscious, but emotionel, crying readily when asked about himself. His mother said that before the fit he complained of not being able to swallow, and of tightness in the throat. Later, he was found to have characteristically choreic movements, his speech was imperfect, there was no anmsthesia, and no heart affection. On January 22 nd he complained of a lump in his throat, and very soon he jumped up, and would have fallen out of bed if he had not been caught. $\mathrm{He}$ rolled over on his face, sobbing. When he was turned over, his back became quite rigid, and he worked his limbs about. He did not lose consciousness. He was discharged cured on January 318t.

Remarks.-Emotional disturbance is common enough in chores, but the hysteroid convulsive attacks which occurred in this boy are probebly rare. Unfortunately there is no record of the family history, nor of the previous history of the condition of the patient.

vî., VI. 